\title{
Reassessing the BODE score as a criterion for listing COPD patients for lung transplantation
}

This article was published in the following Dove Press journal:

International Journal of COPD

\section{Lionel Pirard' \\ Eric Marchand ${ }^{1,2}$}

'Service de Pneumologie, Department of Pneumology, Institut de Recherche Expérimentale et Clinique (IREC), UCLouvain, CHU-UCL-Namur, Site Godinne, Yvoir, Belgium; ' 2 Laboratoire de Physiologie Respiratoire, URPhyM, Namur Research Life Institute for Life Sciences (NARILIS), Université de Namur, Namur, Belgium
Correspondence: Eric Marchand Service de Pneumologie, CHU-UCLNamur, Site Godinne, Avenue Dr Gaston Thérasse I, 5530 Yvoir, Belgium Tel +328142335 I

Fax +32 8I423352

Email eric.marchand@uclouvain.be
Background: The BODE score (incorporating body mass index, airflow obstruction, dyspnea and exercise capacity) is used for the timing of listing for lung transplantation (LTx) in COPD, based on survival data from the original BODE cohort. This has limitations, because the original BODE cohort differs from COPD patients who are candidates for LTx and the BODE does not include parameters that may influence survival. Our goal was to assess whether parameters such as age, smoking status and diffusion indices significantly influence survival in the absence of LTx, independently of the BODE.

Methods: In the present cohort study, the BODE was prospectively assessed in COPD patients followed in a tertiary care hospital with an LTx program. The files of 469 consecutive patients were reviewed for parameters of interest (age, gender, smoking status and diffusing capacity of the lungs for carbon monoxide [DL,CO]) at the time of BODE assessment, as well as for survival status. Their influence on survival independent of the BODE score was assessed, as well as their ability to predict survival in patients aged less than 65 years.

Results: A Cox regression model showed that the BODE score, age and DL,CO were independently related to survival ( $P$-values $<0.001$ ), as opposed to smoking status. Survival was better in patients aged less than 65 in the first $(P=0.004)$, third $(P=0.002)$ and fourth BODE quartiles $(P=0.008)$. The difference did not reach significance in the second quartile $(P=0.13)$. Median survival for patients aged less than 65 in the fourth BODE quartile was 55 months. According to a receiver operating characteristic curve analysis, the BODE score as well as $\mathrm{FEV}_{1}$ and DL,CO fared similarly in predicting survival status at 5 years in patients aged less than 65 years.

Conclusion: Age and DL,CO add to the BODE score to predict survival in COPD. Assessing survival using tools tested in cohorts of patients younger than 65 years is warranted for improving the listing of patients for LTx.

Keywords: age, DL, CO, BODE index, survival, COPD, smoking status, gender

\section{Introduction}

COPD is a common, preventable and treatable disease characterized by persistent respiratory symptoms and airflow limitation due to airway and alveolar abnormalities caused by exposure to noxious particles or gases. ${ }^{1}$ COPD is a major cause of mortality, being the fourth leading cause of death worldwide with more than 3 million annual deaths. $^{2}$

Various tools have been developed to predict mortality in patients with COPD. In a clinical setting, these are mostly useful in the context of lung transplantation (LTx), for which COPD is the first indication. ${ }^{3}$ Indeed, it is recommended to list a patient for LTx if transplantation is expected to provide a survival advantage over optimal medical treatment. ${ }^{4}$ In COPD patients, $\mathrm{FEV}_{1}$ has been recognized as a determinant 
of survival since Fletcher and Peto's landmark study, ${ }^{5}$ later confirmed by other large studies including the Intermittent Positive Pressure Breathing (IPPB) trial, where FEV 1 and age were the best predictors of mortality. ${ }^{6}$

More recently, other parameters such as dyspnea, ${ }^{7}$ the Six-Minute Walk Test distance ${ }^{8}$ and body mass index (BMI $)^{9}$ were shown to be independently associated with survival. This led to the development of multidimensional indices such as the BODE. The BODE is a $0-10$ scale based on the BMI (B), the degree of airflow obstruction (O; assessed by $\mathrm{FEV}_{1}$ ), dyspnea (D; assessed by the mMRC dyspnea scale) and exercise capacity (E; assessed by the Six-Minute Walk Test distance). In their seminal paper, Celli et al showed that the BODE score was a better predictor of mortality than $\mathrm{FEV}_{1} \cdot{ }^{10}$

The BODE is recommended as a criterion for both referral (BODE score $=5-6$ ) and listing (BODE score $\geq 7$ ) of COPD patients for LTx. ${ }^{3,11}$ This recommendation of the International Society for Heart and Lung Transplantation (ISHLT) is based on the median survival of 37 months for patients with a BODE score $\geq 7$ in the original publication of Celli et al. ${ }^{10}$ This is worse than the current expected 6 years' median survival after LTx. ${ }^{12}$ Lahzami et al compared the survival of their transplanted COPD patients with that of patients from the BODE cohort. This led them to state that using a BODE score $\geq 7$ indeed conferred a survival advantage for LTx. ${ }^{13}$

The study by Lahzami et $\mathrm{al}^{13}$ and the recommendation by the ISHLT, however, have several shortcomings. ${ }^{14}$ First, the BODE cohort differs from the population assessed for LTx listing. In particular, the BODE cohort was not limited to patients aged less than 65 years, which is usually a criterion for LTx. Furthermore, active smokers were not excluded from the BODE cohort, while sustained smoking cessation is required for $\mathrm{LTx} .{ }^{3,10}$ In addition, the original BODE cohort included only $7 \%$ women. ${ }^{15}$

As $\mathrm{FEV}_{1}$ does not describe the full picture of pulmonary function alterations in COPD, there is also a rationale to assess other lung function parameters for the prediction of survival. In particular, the diffusing capacity of the lungs for carbon monoxide (DL,CO; also known as the carbon monoxide transfer factor) has been shown to be an independent predictor of survival. ${ }^{16}$

Accordingly, the aims of the present study were to test whether age, smoking status, gender and DL,CO added to the BODE score for the prediction of survival in COPD in a cohort of patients with a large disease severity scatter. In a second step, as age indeed added to the BODE score, we were interested in assessing the value of the BODE as well as other potential parameters for predicting survival at 5 years in patients aged less than 65 years, since this is the age limit generally considered for LTx. ${ }^{12}$

\section{Methods}

This was a retrospective cohort study of COPD patients with a prospective BODE score assessment.

\section{Study population}

Files of patients with a BODE assessment at the outpatient COPD clinic of the CHU-UCL-Namur (Site Godinne) were retrospectively retrieved. The CHU-UCL-Namur is a tertiary care hospital with an LTx program. Inclusion in the study required a history of smoking ( $>10$ pack-years) and a clinical diagnosis of COPD confirmed by spirometry according to the modified GOLD criteria (post-bronchodilator $\mathrm{FEV}_{1} / \mathrm{FVC}$ below the lower limit of normal).

The files of 487 consecutive patients with a BODE assessment were reviewed. Patients were excluded $(n=18)$ if they had no smoking history, known active or recent ( $<5$ years) neoplastic disease, or chronic heart failure with left ventricular ejection fraction $<40 \%$, leaving 469 patients for the analysis.

\section{Study measurements}

The BODE was prospectively assessed as a routine in the outpatient COPD clinic. Files of patients with a BODE measurement between September 2009 and May 2013 were reviewed. Moreover, the files of the patients were reviewed for gender, age, smoking status (current or ex-smoker) and pulmonary function test parameters at the time of BODE assessment, as well as for survival status. If data were available for the BODE score calculation before September 2009, the BODE score was calculated at that time, which was used as study inclusion. Spirometry and gas transfer were measured using a HypAir System (Medisoft, Sorinnes, Belgium). Quality control followed accepted guidelines, with DL,CO gas analyzer calibrations being carried out prior to each session and volume calibrations daily. Owing to the retrospective nature of the data analysis, DL,CO was missing at the time of BODE assessment in 33 patients. Predicted values are those of the European Coal and Steel Community. ${ }^{17}$ The Six-Minute Walk Test was performed according to guidelines. ${ }^{18}$

Patients were censored at the time of last contact or LTx for the survival analysis. Survival status was determined up to May 2018 from medical files, including those of referring physicians, as well as from obituary websites. 


\section{Statistical analysis}

Statistical analysis was performed using the NCSS software version 11 (NCSS, LLC, Kaysville, UT, USA) for Windows 7 (Microsoft Corporation, Redmond, WA, USA). Data (including percent predicted values) are presented as mean \pm SD or absolute numbers. Differences between groups were assessed using an independent samples $t$-test, ANOVA or the chisquared model, where appropriate. The parameters found to be significantly associated with survival in univariate analysis were subsequently entered in a multivariate Cox proportional hazard regression analysis model. The BODE score, $\mathrm{FEV}_{1}$ and DL,CO were entered in the survival analysis as categorical variables (quartiles). The same was done for age $(<65$ or $\geq 65$ years). The calculated BODE IQRs were the same as in the study by Celli et al. ${ }^{10}$ An additional Cox proportional hazard regression analysis was performed with age, BODE score, $\mathrm{FEV}_{1}$ and $\mathrm{DL}, \mathrm{CO}$ analyzed as continuous variables. The median survival was calculated using the Kaplan-Meier method. Determinants of survival at 5 years were assessed by the receiver operating characteristic (ROC) curve method. A transformation of the BODE was used for this analysis (10-BODE score) in order for lower values to be predictive of survival outcome. Since this analysis was intended to assess LTx listing criteria, it was restricted to patients aged less than 65 years. Moreover, patients alive and censored less than 5 years after inclusion were excluded from this analysis.

A level of $P<0.05$ was considered statistically significant.

The study was accepted by the ethics committee of the CHU-UCL-Namur (approval 149/2015). Because of the retrospective nature of the analysis, the ethics committee considered that patient consent was not required. Patient data confidentiality was respected at all steps of the study, which was conducted in accordance with the Declaration of Helsinki.

\section{Results}

The study population comprised 469 patients. The main characteristics at the time of BODE assessment are described in Table 1. There was a good representation of both genders and GOLD stages II-IV.

During the follow-up, 60 patients (13\%) underwent LTx after a mean of 33 months (IQR 16-45) and were censored at that time for the survival analysis. Moreover, 170 (36\%) died without LTx after a mean of 42 months (IQR 22-58). There were 239 patients alive without LTx at the last survival status assessment, with a mean follow-up of 63 months (IQR 50-85).

Characteristics of the patients according to survival or LTx status are shown in Table 2. As expected, age was lower
Table I Patient characteristics at the time of BODE assessment

\begin{tabular}{|l|l|}
\hline$n$ & 469 \\
\hline Gender (F/M) & $179 / 290$ \\
\hline Age (years) & $63 \pm 9$ \\
\hline Current/ex-smokers & $145 / 324$ \\
\hline Post-BD FEV, (L) & $1.22 \pm 0.62$ \\
\hline Post-BD FEV $(\%)$ & $45 \pm 20$ \\
\hline Post-BD FEV,/FVC & $0.44 \pm 0.13$ \\
\hline DL,CO (\%) & $47 \pm 24$ \\
\hline GOLD stage (I-IV) & $25 / 150 / 163 / 131$ \\
\hline BODE & $4.0 \pm 2.4$ \\
\hline BODE quartile (I-4) & $139 / / 29 / 1 / 9 / 82$ \\
\hline
\end{tabular}

Notes: Data are presented as absolute numbers or mean \pm SD. ${ }^{a} n=436$.

Abbreviations: $\mathrm{BD}$, bronchodilator; $\mathrm{BODE}$, body mass index, airflow obstruction, dyspnea and exercise capacity; DL,CO, diffusing capacity of the lungs for carbon monoxide; $F$, female; $M$, male; \%, percent predicted.

in survivors and patients who underwent LTx. The BODE was lower in survivors and higher in transplanted patients; the reverse was true for pulmonary function indices.

As shown in Table 3, the BODE score was strongly associated with survival in univariate analysis. As expected, $\mathrm{FEV}_{1}$ was also associated with survival, with the association being stronger when expressed as an absolute value rather than percent predicted. Moreover, age and DL,CO were also strongly associated with survival in univariate analysis. However, there was no significant association with smoking status or gender.

As $\mathrm{FEV}_{1}$ is one component of the BODE, it was not included in the multivariate model. The multivariate analysis showed that age and DL,CO (both expressed as categorical variables) were predictors of survival, independent of the BODE score.

A Cox regression model including the BODE score, age and $\mathrm{DL}, \mathrm{CO}$ as continuous variables confirmed that these parameters were strongly and independently related to survival (all $P$-values $<0.001$ ).

Survival was significantly better for patients aged less than 65 years in each BODE quartile (Table 4, Figure 1) except for the second quartile, where the same tendency was observed without reaching statistical significance. Median survival for patients younger than 65 years in the BODE fourth quartile ( $\mathrm{n}=63$ ) was 55 months (95\% CI 40-65 months); this outcome was very similar (55 months; $95 \%$ CI 40-59 months) when active smokers at the time of BODE assessment ( $\mathrm{n}=9$ ) were excluded from this subgroup analysis.

As can be seen from Table 5 and Figure 2, the ROC analysis for the prediction of survival status at 5 years showed similar areas under the curve (AUCs) for the BODE score, 
Table 2 Patient characteristics at baseline according to survival or transplantation status

\begin{tabular}{|c|c|c|c|c|}
\hline & Survived & Died & Transplanted & $P$-value \\
\hline $\mathrm{n}$ & 239 & 170 & 60 & \\
\hline Gender (F/M) & $91 / 148$ & $58 / 112$ & $30 / 30$ & 0.09 \\
\hline Age (years) & $62 \pm 9$ & $66 \pm 10$ & $57 \pm 5$ & $<0.0001$ \\
\hline Current/ex-smokers & $90 / 149$ & $50 / 120$ & $5 / 55$ & $<0.0001$ \\
\hline BODE & $2.9 \pm 2.0$ & $4.7 \pm 2.3$ & $6.3 \pm 1.4$ & $<0.0001$ \\
\hline BODE quartile $(I-4)$ & III/77/37/I4 & $28 / 47 / 54 / 4 \mid$ & $0 / 5 / 28 / 27$ & $<0.0001$ \\
\hline Post-BD FEV, (L) & $1.45 \pm 0.64$ & $1.08 \pm 0.53$ & $0.66 \pm 0.21$ & $<0.0001$ \\
\hline Post-BD FEV,$(\%)$ & $53 \pm 19$ & $4 I \pm 17$ & $24 \pm 7$ & $<0.0001$ \\
\hline Post-BD FEV,/FVC & $0.48 \pm 0.12$ & $0.43 \pm 0.12$ & $0.30 \pm 0.07$ & $<0.000$ I \\
\hline DL,CO (\%) & $56 \pm 23$ & $4 I \pm 22$ & $27 \pm 12$ & $<0.0001$ \\
\hline
\end{tabular}

Note: Data are presented as absolute numbers or mean $\pm S D$.

Abbreviations: BD, bronchodilator; BODE, body mass index, airflow obstruction, dyspnea and exercise capacity; DL,CO, diffusing capacity of the lungs for carbon monoxide; $\mathrm{F}$, female; $\mathrm{M}$, male; \%, percent predicted.

$\mathrm{FEV}_{1}$ (whether expressed as absolute values or percent predicted) and DL,CO. There were no significant differences between these predictors of survival at 5 years, although the difference between the AUCs for the BODE and $\mathrm{FEV}_{1}(\mathrm{~L})$ tended to favor the former $(P=0.051)$.

\section{Discussion}

In this large cohort of 469 COPD patients with a good representation of moderate to very severe disease and both genders, we found that age and DL,CO significantly and independently added to the BODE for the prediction of survival.

To our knowledge, only two studies have previously tested the added value of age to the BODE for the prediction of survival in COPD. From the data gathered from the medical therapy arm of the National Emphysema Treatment Trial (NETT), Martinez et al identified several factors associated with an increased mortality. They showed that older age, but also lowered DL,CO and higher residual volume, significantly added to the BODE to predict survival. ${ }^{19}$
By design, the NETT was restricted to very selected patients with severe or very severe COPD and the BODE score was a proxy since dyspnea was assessed by the University of California San Diego Shortness of Breath Questionnaire rather than by the mMRC scale. Our results extend these findings to a broader range of COPD severity. In contrast, Casanova et al did not find any independent effect of age on top of the BODE in a cohort of patients with mostly severe to very severe $\mathrm{COPD} .^{20}$

As age was an independent predictor of survival in the present study as well as in the NETT cohort, this suggests that relying on survival data from the BODE cohort may overestimate the survival advantage of LTx when listing patients on the BODE criterion. In the present cohort, survival was significantly better in patients aged less than 65 years for each BODE quartile except for the second, where we also observed a strong tendency for better survival in younger patients. This extends the findings of Reed et $\mathrm{al},{ }^{15}$ who analyzed the survival of patients in the fourth quartile

Table 3 Univariate and multivariate Cox regression models for survival analysis

\begin{tabular}{|c|c|c|c|c|c|c|}
\hline & \multicolumn{3}{|c|}{ Univariate analysis } & \multicolumn{3}{|c|}{ Multivariate analysis } \\
\hline & $\mathbf{R R}$ & $95 \% \mathrm{Cl}$ & $P$-value & $\mathbf{R} \mathbf{R}$ & $95 \% \mathrm{Cl}$ & $P$-value \\
\hline Age ( $\geq 65$ vs $<65$ years) & 1.62 & $1.20-2.19$ & 0.0017 & 1.92 & $1.39-2.66$ & 0.0001 \\
\hline BODE (4th vs Ist-3rd quartiles) & 3.24 & $2.25-4.65$ & $<0.001$ & 2.52 & $1.6 \mathrm{I}-3.94$ & 0.0001 \\
\hline $\mathrm{DL}, \mathrm{CO}(\%)$ (I st vs 2 nd-4th quartiles) & 3.33 & $2.34-4.75$ & $<0.001$ & 2.75 & I.84-4.I & $<0.000$ I \\
\hline $\mathrm{FEV}_{1}$ (L) (Ist vs 2nd-4th quartiles) & 2.94 & $2.12-4.09$ & $<0.001$ & & & \\
\hline $\mathrm{FEV}_{1}$ (\%) (I st vs 2 nd -4 th quartiles) & 1.85 & $1.31-2.62$ & $=0.001$ & & & \\
\hline Gender ( $M$ vs $F$ ) & 1.12 & $0.82-1.54$ & 0.47 & & & \\
\hline Smoker (current vs ex) & 1.15 & $0.83-1.6$ & 0.40 & & & \\
\hline
\end{tabular}

Abbreviations: BODE, body mass index, airflow obstruction, dyspnea and exercise capacity; DL,CO, diffusing capacity of the lungs for carbon monoxide; $F$, female; $M$, male; $\%$, percent predicted; RR, risk ratio for death. 
Table 4 Survival difference according to BODE quartile and age

\begin{tabular}{|c|c|c|c|c|c|c|}
\hline & \multicolumn{2}{|c|}{ Age $<65$ years } & \multicolumn{2}{|c|}{ Age $\geq 65$ years } & \multirow{2}{*}{$\begin{array}{l}\text { HR for death } \\
\text { ( }<65 \text { vs } \geq 65 \text { years) }\end{array}$} & \multirow[t]{2}{*}{$P$-value } \\
\hline & $n$ & $\begin{array}{l}\text { Median survival } \\
\text { (months) }\end{array}$ & $n$ & $\begin{array}{l}\text { Median survival } \\
\text { (months) }\end{array}$ & & \\
\hline BODE QI & 75 & & 62 & & $0.31(0.15-0.66)$ & 0.004 \\
\hline BODE Q2 & 71 & & 58 & $80(62-132)$ & $0.65(0.36-1.15)$ & 0.13 \\
\hline BODE Q3 & 81 & $67.5(56-7 I)$ & 33 & $51(38-58)$ & $0.45(0.24-0.82)$ & 0.002 \\
\hline BODE Q4 & 63 & $55(40-65)$ & 19 & $38(13-42)$ & $0.44(0.21-0.92)$ & 0.008 \\
\hline
\end{tabular}

Abbreviations: BODE, body mass index, airflow obstruction, dyspnea and exercise capacity; QI-4, quartiles I-4.

of BODE listed for LTx in the United Network of Organ Sharing (UNOS) database. These patients had a significantly better survival than the patients in the BODE fourth quartile from the original cohort of Celli et al. ${ }^{10}$ In the present study, the median survival of patients aged less than 65 years in the BODE fourth quartile was 55 months. This contrasts with the median survival of 37 months in the BODE validation cohort, ${ }^{10}$ but fits very well with the median survival of 59 months observed in the UNOS cohort of patients listed for LTx with a BODE score in the fourth quartile. ${ }^{15}$
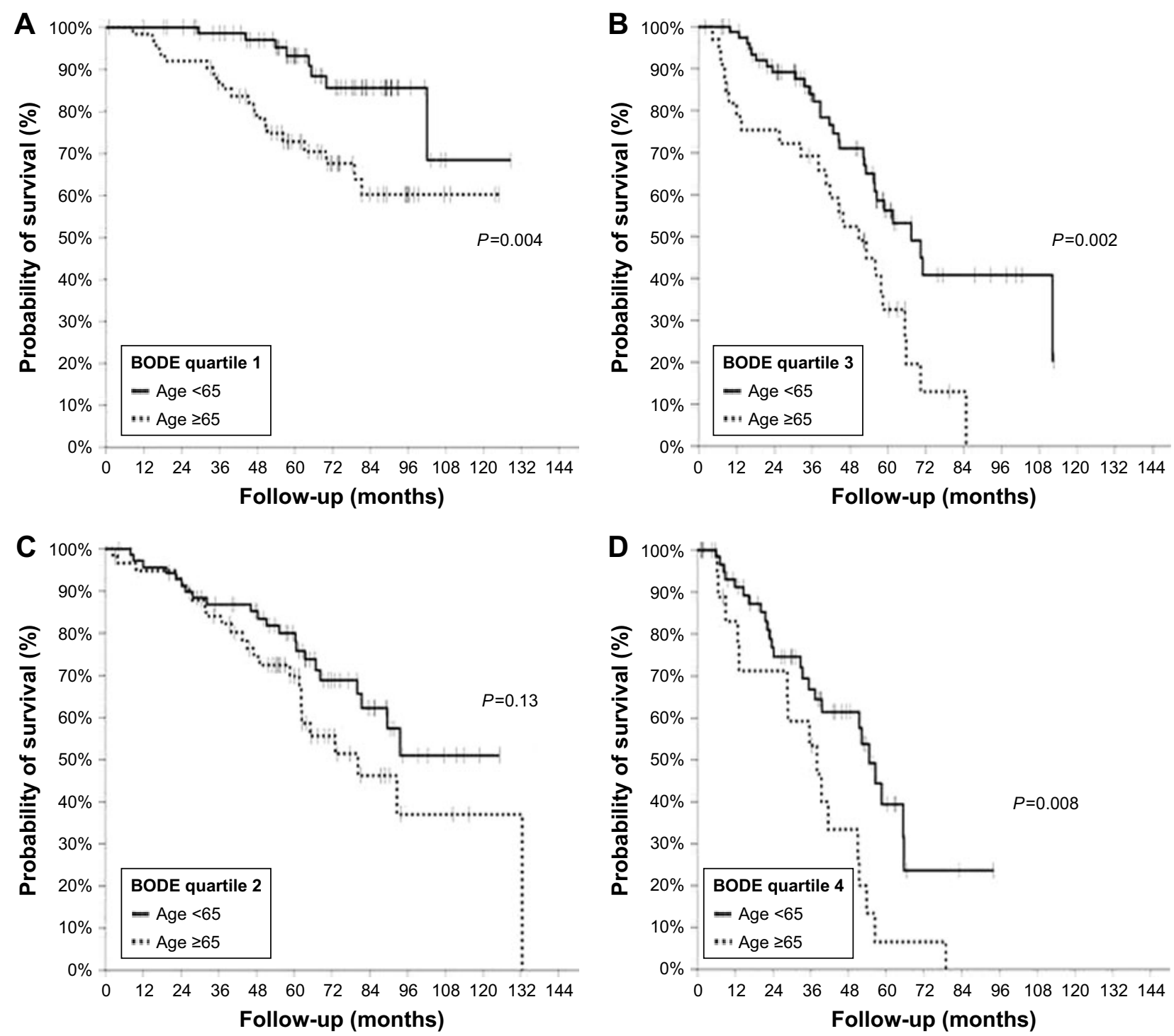

Figure I Kaplan-Meier survival curves in BODE quartiles I (A), 2 (B), 3 (C) and 4 (D) in patients aged $<65$ years (continuous lines) or $\geq 65$ years (dotted lines). Abbreviation: BODE, body mass index, airflow obstruction, dyspnea and exercise capacity. 
Table 5 ROC curve analysis for predicting survival status at 5 years in patients aged $<65$ years $(n=\mid 49)$

\begin{tabular}{|l|l|}
\hline Parameter & AUC $(95 \%$ CI) \\
\hline Post-BD FEV $_{\text {, (L) }}$ & $0.73(0.63-0.8 I)$ \\
\hline Post-BD FEV,$(\%)$ & $0.76(0.67-0.83)$ \\
\hline DL,CO (\%) & $0.75(0.65-0.83)$ \\
\hline BODE & $0.78(0.69-0.85)$ \\
\hline
\end{tabular}

Abbreviations: $\mathrm{AUC}$, area under the curve; $\mathrm{BD}$, bronchodilator; $\mathrm{BODE}$, body mass index, airflow obstruction, dyspnea and exercise capacity; DL,CO, diffusing capacity of the lungs for carbon monoxide; \%, percent predicted; ROC, receiver operating characteristic.

A limitation of the UNOS database study is the absence of dyspnea assessment by the mMRC score.

Altogether, these results strongly suggest that using the BODE score in the LTx selection process for COPD should rely on data retrieved from cohorts of patients younger than 65 years. Fortunately, even if the survival benefit of LTx is overestimated when using data from the BODE cohort, our data and those of the UNOS database still suggest a survival benefit in the fourth quartile of BODE in patients aged less than 65 years. Indeed, according to data from the ISHLT registry, the median survival after adult LTx is 6 years, ${ }^{12}$ and 5.8 years in those transplanted for COPD. ${ }^{4}$

Some programs now offer LTx for patients aged up to 70 years, or even more. However, these patients are more likely to be denied LTx in the presence of relative contraindications than younger patients. Accordingly, a comparison of

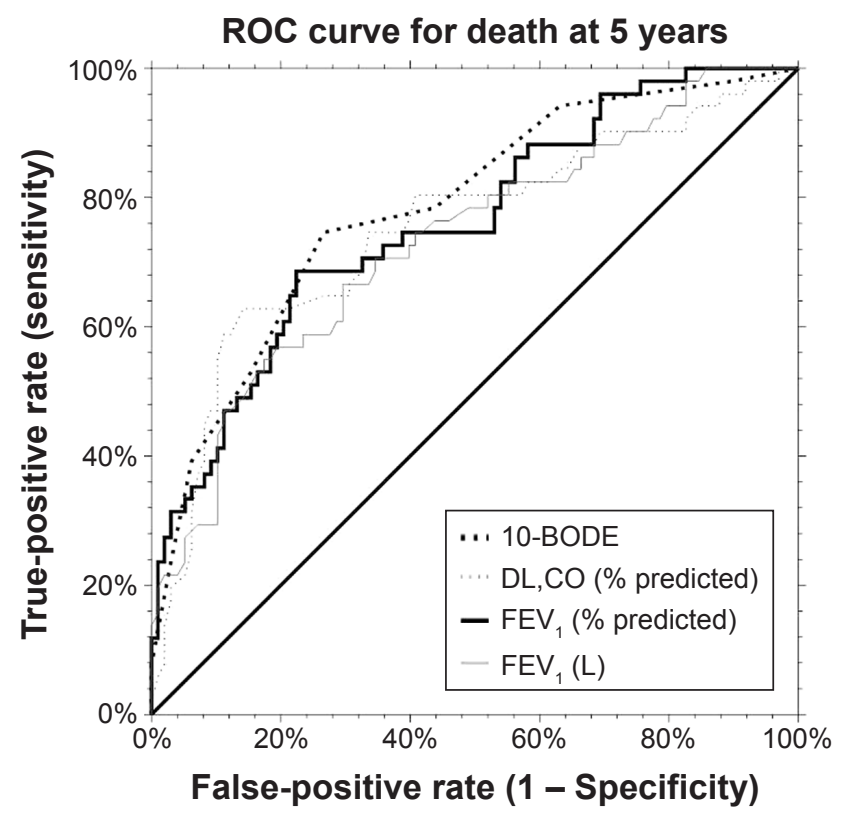

Figure 2 ROC curve analysis for the prediction of death at 5 years according to BODE score, FEV (L) or DL,CO (\% predicted).

Abbreviations: BODE, body mass index, airflow obstruction, dyspnea and exercise capacity; DL,CO, diffusing capacity of the lungs for carbon monoxide; ROC, receiver operating characteristic. survival with a population selected according to the absence of absolute contraindication for LTx, as in the present study, would be of doubtful significance.

As $\mathrm{FEV}_{1}$ addresses only some aspects of the functional derangements of the respiratory system associated with $\mathrm{COPD}$, there is a rationale to assess the relationship between survival and other respiratory function parameters. We found that DL,CO significantly added to the BODE index to predict survival. This is in line with the results of Boutou et al, ${ }^{16}$ who showed that DL,CO was the only functional parameter related to mortality in a multivariate analysis. Of note, $\mathrm{FEV}_{1}$ was not independently related to survival in this cohort, but this may be due to the fact that the majority of the included patients had very severe airway obstruction (GOLD stage IV) ${ }^{16}$ Few other studies have assessed the association between DL,CO and survival in patients with COPD, but two such studies confirmed an independent association with survival. ${ }^{19,21}$ Our data extend these findings by showing that DL, CO adds to the BODE to predict survival in a cohort with a larger spectrum of disease severity.

As the median survival after adult LTx is 6 years, ${ }^{12}$ we looked at the ability of different parameters to predict survival at 5 years in patients aged less than 65 years using ROC curve analysis. The highest AUC values were observed for the BODE score as well as $\mathrm{FEV}_{1}$ (\% predicted). However, no significant difference was observed between the AUC for $\mathrm{FEV}_{1}$ (whether expressed as absolute value or percent predicted), DL,CO or the BODE score. The AUC of all these parameters could be considered as acceptable for the discrimination of surviving patients at 5 years. ${ }^{22}$ However, with the highest value at 0.78 , there is room for improvement. This would require studying a larger population of COPD patients aged less than 65 years without severe comorbidity, and combining the BODE with other parameters of interest such as DL,CO.

Our study has several strengths and limitations. It includes a large population with a diversity of airflow obstruction severity and a long follow-up. This is a singlecenter cohort from a tertiary care hospital. This may limit the generalizability of the results. The retrospective nature of the analysis may also be viewed as a weakness. However, the measurements taken were a reflection of daily practice, and the primary endpoint of the study (all-cause mortality) is robust and unlikely to be subject to bias.

\section{Conclusion}

In a large cohort of COPD patients, we found that increased age and lowered DL,CO, but neither smoking status nor gender, added to the BODE to predict survival. The data from 
the original BODE cohort underestimate mortality when used in candidates for LTx. A BODE score $\geq 7$, however, remains an acceptable criterion for listing patients on the waiting list. Testing other multidimensional indices in patients younger than 65 years with no severe comorbidities deserves more studies to improve the selection process for LTx in patients with COPD.

\section{Abbreviations}

AUC, area under the curve; BMI, body mass index; BODE, body mass index, airflow obstruction, dyspnea and exercise capacity; DL,CO, diffusing capacity of the lungs for carbon monoxide; ISHLT, International Society for Heart and Lung Transplantation; LTx, lung transplantation; NETT, National Emphysema Treatment Trial; ROC, receiver operating characteristic; UNOS, United Network of Organ Sharing.

\section{Acknowledgment}

The authors thank Sarah Boulanger for survival data collection in the present work.

\section{Author contributions}

Both authors contributed to data analysis, drafting and revising the article, gave final approval of the version to be published, and agree to be accountable for all aspects of the work.

\section{Disclosure}

The authors report no conflicts of interest in this work.

\section{References}

1. Global Initiative for Chronic Obstructive Lung Disease. Global strategy for the diagnosis, management, and prevention of chronic obstructive pulmonary disease. 2018 Report. Available from: https://goldcopd.org/ wp-content/uploads/2017/11/GOLD-2018-v6.0-FINAL-revised-20Nov_WMS.pdf. Accessed November 8, 2018.

2. GBD 2015 Chronic Respiratory Disease Collaborators. Global, regional, and national deaths, prevalence, disability-adjusted life years, and years lived with disability for chronic obstructive pulmonary disease and asthma, 1990-2015: a systematic analysis for the Global Burden of Disease Study 2015. Lancet Respir Med. 2017;5(9):691-706.

3. Weill D, Benden C, Corris PA, et al. A consensus document for the selection of lung transplant candidates: 2014 - an update from the Pulmonary Transplantation Council of the International Society for Heart and Lung Transplantation. J Heart Lung Transplant. 2015;34(1):1-15.
4. International Society for Heart and Lung Transplantation. Adult Lung Transplantation Statistics. [Slide kit]; 2017. Available from: https://ishltregistries.org/downloadables/slides/2017/lung_adult.pptx. Accessed November 8, 2018.

5. Fletcher C, Peto R. The natural history of chronic airflow obstruction. Br Med J. 1977;1(6077):1645-1648.

6. Anthonisen NR, Wright EC, Hodgkin JE. Prognosis in chronic obstructive pulmonary disease. Am Rev Respir Dis. 1986;133(1):14-20.

7. Nishimura K, Izumi T, Tsukino M, Oga T. Dyspnea is a better predictor of 5-year survival than airway obstruction in patients with COPD. Chest. 2002;121(5):1434-1440.

8. Pinto-Plata VM, Cote C, Cabral H, Taylor J, Celli BR. The 6-min walk distance: change over time and value as a predictor of survival in severe COPD. Eur Respir J. 2004;23(1):28-33.

9. Schols AM, Broekhuizen R, Weling-Scheepers CA, Wouters EF. Body composition and mortality in chronic obstructive pulmonary disease. Am J Clin Nutr. 2005;82(1):53-59.

10. Celli BR, Cote CG, Marin JM, et al. The body-mass index, airflow obstruction, dyspnea, and exercise capacity index in chronic obstructive pulmonary disease. $N$ Engl J Med. 2004;350(10):1005-1012.

11. Lane CR, Tonelli AR. Lung transplantation in chronic obstructive pulmonary disease: patient selection and special considerations. Int $J$ Chron Obstruct Pulmon Dis. 2015;10:2137-2146.

12. Chambers DC, Yusen RD, Cherikh WS, et al. The Registry of the international society for heart and lung transplantation: thirty-fourth adult lung and heart-lung transplantation report-2017; focus theme: allograft ischemic time. J Heart Lung Transplant. 2017;36(10):1047-1059.

13. Lahzami S, Bridevaux PO, Soccal PM, et al. Survival impact of lung transplantation for COPD. Eur Respir J. 2010;36(1):74-80.

14. Marchand E. The BODE index as a tool to predict survival in COPD lung transplant candidates. Eur Respir J. 2010;36(6):1494-1495.

15. Reed RM, Cabral HJ, Dransfield MT, et al. Survival of lung transplant candidates with COPD: BODE score reconsidered. Chest. 2018;153(3): 697-701.

16. Boutou AK, Shrikrishna D, Tanner RJ, et al. Lung function indices for predicting mortality in COPD. Eur Respir J. 2013;42(3):616-625.

17. Quanjer PH, Tammeling GJ, Cotes JE, Pedersen OF, Peslin R, Yernault JC. Lung volumes and forced ventilatory flows. Report Working Party Standardization of Lung Function Tests, European Community for Steel and Coal. Official Statement of the European Respiratory Society. Eur Respir J Suppl. 1993;16:5-40.

18. Holland AE, Spruit MA, Troosters T, et al. An official European Respiratory Society/American Thoracic Society technical standard: field walking tests in chronic respiratory disease. Eur Respir J. 2014;44(6): $1428-1446$

19. Martinez FJ, Foster G, Curtis JL, et al. Predictors of mortality in patients with emphysema and severe airflow obstruction. Am J Respir Crit Care Med. 2006;173(12):1326-1334.

20. Casanova C, Cote C, de Torres JP, et al. Inspiratory-to-total lung capacity ratio predicts mortality in patients with chronic obstructive pulmonary disease. Am J Respir Crit Care Med. 2005;171(6):591-597.

21. Haruna A, Muro S, Nakano Y, et al. CT scan findings of emphysema predict mortality in COPD. Chest. 2010;138(3):635-640.

22. Hosmer DW, Lemeshow S. Area under the ROC curve. In Applied Logistic Regression. 2nd edn. New York: John Wiley; 2000:160-164. 
International Journal of COPD

Dovepress

\section{Publish your work in this journal}

The International Journal of COPD is an international, peer-reviewed journal of therapeutics and pharmacology focusing on concise rapid reporting of clinical studies and reviews in COPD. Special focus is given to the pathophysiological processes underlying the disease, intervention programs, patient focused education, and self management protocols.

This journal is indexed on PubMed Central, MedLine and CAS. The manuscript management system is completely online and includes a very quick and fair peer-review system, which is all easy to use. Visit http://www.dovepress.com/testimonials.php to read real quotes from published authors.

Submit your manuscript here: http://www.dovepress.com/international-journal-of-chronic-obstructive-pulmonary-disease-journal 